\title{
Preparation of Activated Charcoal Adsorbent from Waste Tire
}

\author{
Vinay Kumar Jha* and Kiran Subedi \\ Central Department of Chemistry, Tribhuvan University, Kirtipur, Kathmandu, Nepal \\ E-mail:vinayj2@yahoo.com
}

\begin{abstract}
Activated charcoal was prepared from waste tire by using pyrolysis technique in three different atmospheres, viz, air, nitrogen and a combined atmosphere of nitrogen and water (steam). Methylene blue was then adsorbed on to these activated charcoals and the kinetics of adsorption was also studied. The adsorption isotherms of methylene blue were simulated by the mathematical equations of Langmuir and Freundlich. The Langmuir isotherms were found to have better fitting than that of Freundlich. The Qmax values obtained from Langmuir model were 0.032, 0.036, and $0.092 \mathrm{mmol} / \mathrm{g}$ for the activated charcoals prepared in air, nitrogen and nitrogen and water (steam), respectively. The overall reaction was found to be pseudo-second order with the rate constant of $4.2 \times 10-2 \mathrm{~L} \mathrm{g/(mmolmin})$. The equilibrium adsorption value obtained from the kinetics data i.e. 0.072 ( $\mathrm{mmol} / \mathrm{g})$ was found to be comparable with that obtained from Langmuir model.
\end{abstract}

Keywords: Waste tire; Activated charcoal; Methylene blue; Adsorption isotherms; Kinetics of adsorption

\section{Introduction}

The world is currently facing a solid waste dilemma for which all elements of society are responsible. There has been a continual, steady rise in the volumes of waste generated by every person. Local authorities and private companies are finding it increasingly difficult to identify new facilities to accommodate these volumes. The environmentally acceptable management of redundant tires, which is a category of solid waste and globally more than three million tires are discarded every year and accumulated over years, is a concern throughout the world ${ }^{1}$. In the absence of cost-effective technology to completely reutilize the materials used in tire manufacture, disposal to landfill continues to remain the only practical solution. This however presents its own unique problems. The properties that make them desirable as tires, most notably durability, also make their disposal and reprocessing difficult as they are almost immune to biological degradation ${ }^{2}$.

Burning tires in roads and highways results in the emission of large amounts of thick black smoke and noxious which is a major source of air pollutant in Nepal. Furthermore, the disposal of tires is also becoming more expensive and this trend is likely to continue as the landfill space becomes scarcer. A much better solution is to convert such waste tires into valuable products via de-gradation of tires to gaseous or liquid hydrocarbons and solid char residue from

\section{* Corresponding author}


environmental and economic perspective. The waste tire has been utilized for synthesis of activated carbon and thereby adsorption of phenols, basic dyes and metals ${ }^{3,4}$; phenols and $p$ chlorophenols ${ }^{5}$; butane ${ }^{6}$ and natural gas ${ }^{7}$. The most successful attempts to produce high quality adsorbent carbons from waste tires use a two-step process consisting of pyrolysis and activation. Pyrolysis is a common process to convert solid carbonaceous materials into liquid and gaseous hydrocarbons and solid char residue. The principal products from the pyrolysis of waste tires are $33-38 \%$ char, 38-58\% oil and 10-30\% gas. Pyrolysis gases consist primarily of hydrogen, carbon dioxide, carbon monoxide, ethane and butadiene. Other hydrocarbon gases such as propane, propene and butane were found in small quantities ${ }^{8}$.

A physical and chemical route for activation of waste tires are in practice but chemical activation is more expensive than physical activation and furthermore it is time consuming and a bit more rigorous. Thus the purpose of this study was to use physical activation techniques to develop activated charcoal adsorbents from waste tires for application in methylene blue dyes adsorption.

\section{Experimental Methods}

\section{Sample preparation and characterization}

Pieces of waste bicycle tire were collected from the dumping site in Kirtipur, Kathmandu. These pieces were washed, dried and then divided into small chunks. After crushing these pieces to fine dust, it was sieved. The fine tire dust was then subjected to pyrolysis in three different environments namely (1) pyrolysis in open air (Type I), (2) pyrolysis in an inert atmosphere (passage of nitrogen gas) at a pressure of 60 bars and 875 psi (Type II) and (3) pyrolysis in inert atmosphere along with water steam (nitrogen gas and water steam generated at $60^{\circ} \mathrm{C}$ ) (Type III). Thus prepared activated carbon were then weighed and kept in tight impermeable plastic bags separately. The density of each sample was determined with the help of mass to volume ratio. The phase analysis of thus prepared samples was done using XRD.

\section{Adsorption study}

A $500 \mathrm{mg} / \mathrm{L}$ stock solution of methylene blue was prepared using commercial methylene blue dye (BDH, England) without further purification. The various concentration range of methylene blue solutions were prepared by diluting the stock solution. The maximum absorption at wavelength $\left(\lambda_{\max }\right)$ and calibration curve of absorbance as a function of initial concentration of aqueous methylene blue solution were obtained using UV-VIS spectrometer (Elico-CL-27, India).

0.1 gram of activated charcoal was added to $50 \mathrm{ml}$ methylene blue solution with varying concentrations ( 4 to $50 \mathrm{mg} / \mathrm{L}$ ). The mixtures were kept in shaker for four hours. After stirring the mixture was separated and washed. The absorption of supernatant solution was measured by spectrophotometer at the $\lambda_{\max }$ value and then the concentration was calculated with the help of calibration curve. The uptake $\%$ and uptake amount $(\mathrm{mmol} / \mathrm{g})$ were calculated using the following formulae:

$$
\operatorname{Uptake}(\%)=\frac{\mathrm{C}_{\mathrm{i}}-\mathrm{C}_{\mathrm{eq}}}{\mathrm{C}_{\mathrm{i}}} \times 100
$$




$$
\operatorname{Uptake}(\mathrm{mmol} / \mathrm{g})=\frac{\left(\mathrm{C}_{\mathrm{i}}-\mathrm{C}_{\mathrm{eq}}\right)}{\mathrm{M}} \mathrm{V}
$$

where, $\mathrm{C}_{\mathrm{i}}$ and $\mathrm{C}_{\mathrm{eq}}$ are initial and equilibrium concentrations (mmol/L), respectively. $\mathrm{V}$ and $\mathrm{M}$ are volume of the solution (L) and mass of the sample (g), respectively.

\section{Results and Discussion}

\section{Characterization of the activated charcoal}

In going from type I to type III charcoal obtained from waste tire, the physical appearance of color changed from black to brownish while the density was found decreased from 1.14 to $1.05 \mathrm{~g} / \mathrm{ml}$. This decrease of density is related to the increase of the specific surface area of the sample as the inverse of density is the specific volume. The specific surface area was calculated by the following equation ${ }^{3}$ :

$$
\mathrm{S}_{\mathrm{MB}}=\frac{\mathrm{N}_{\mathrm{g}} \times \mathrm{a}_{\mathrm{MB}} \times \mathrm{N} \times 10^{-20}}{\mathrm{M}}
$$

Where $S_{\mathrm{MB}}$ is the specific surface area in $10^{-3} \mathrm{~km}^{2} / \mathrm{kg}, N_{g}$ is the number of molecules of methylene blue adsorbed at the monolayer of fibers in moles $\mathrm{kg}^{-1}$ (or $\mathrm{N}_{\mathrm{g}}=\mathrm{Nm} * \mathrm{M}$ ), $\mathrm{a}_{\mathrm{MB}}$ is the occupied surface area of one molecule of methylene blue $=197.2 \AA^{2}, \mathrm{~N}$ is Avogadro's number $\left(6.023 \times 10^{23} / \mathrm{mol}\right), \mathrm{M}$ is the molecular weight of methylene blue $(373.9 \mathrm{~g} / \mathrm{mol})$ and $\mathrm{N}_{\mathrm{g}}$ (mmol/g) which is equivalent to the $\mathrm{Q}_{\max }$ of Langmuir equation. The specific surface area was increased from 38 to $110 \mathrm{~m}^{2} / \mathrm{g}$ during the process of obtaining activated carbon from type I to type III samples.

\section{Phase analysis}

The x-ray diffraction (XRD) patterns of activated carbon prepared from waste tire are shown in Fig. 1. Some sharp XRD peaks were observed at $2 \theta=26.6^{\circ}, 29.33^{\circ}, 31.0^{\circ}, 31.36^{\circ}$ and $39.36^{\circ}$ for silica $\left(\mathrm{SiO}_{2}\right)$, zinc sulphide $(\mathrm{ZnS})$, magnesium oxide $(\mathrm{MgO})$, respectively. The peaks appeared at $2 \theta=24.82^{\circ}, 39.42^{\circ}$ and $43.16^{\circ}$ were characteristized as activated charcoal ${ }^{9}$. The identified minerals were quartz, anorthite, haemitite and spinel dioxide which are in general used as filler agent in process of tire manufacturing. Several other peaks which are appeared in the XRD patterns but not characterized are unknown.

\section{Adsorption isotherms}

The wavelength corresponding to the maximum absorbance $\left(\lambda_{\max }\right)$ as shown in Fig. 2, was observed at $665 \mathrm{~nm}$ in all concentration ranges which is also in trend with previous report ${ }^{10}$. Hence, this wavelength $\left(\lambda_{\max }=665 \mathrm{~nm}\right)$ was used to obtain the calibration curve of absorbance as a function of methylene blue concentration. The calibration curve of absorbance as a function of methylene blue concentration is shown in Fig. 3. The straight line passing through the origin from the experimental data of concentration-absorbance plot up to the methylene blue concentration of $50 \mathrm{mg} / \mathrm{L}$ indicated the validity of Beer's-Lambert Law for the present setup. 
The data for the adsorption isotherms and kinetics of methylene blue adsorption on activated charcoal prepared from the waste tire were obtained from the calibration curve.

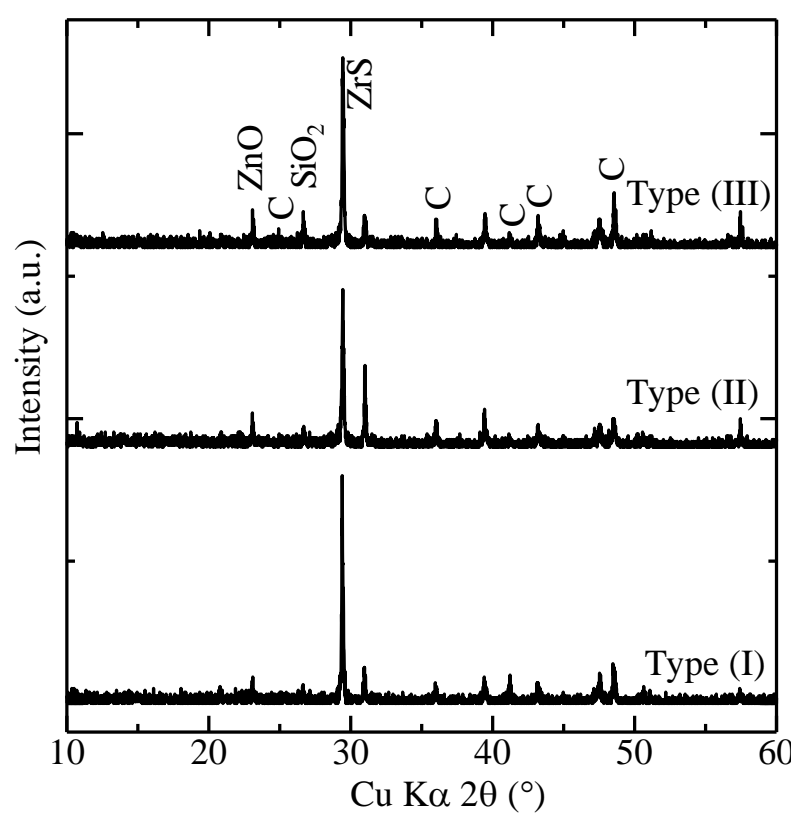

Figure 1 XRD patterns of activated carbons obtained from the activation of waste tire.

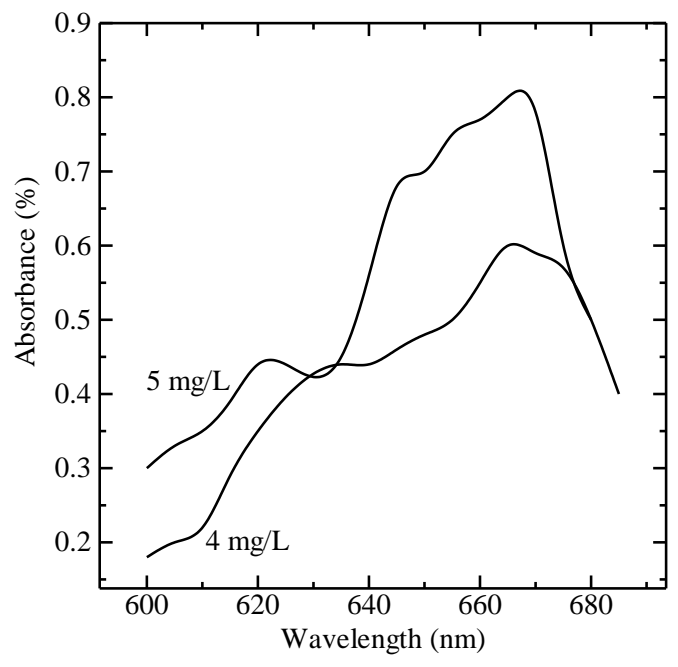

Figure 2 Plot of the absorbance as a function of wavelength for aqueous solution of methylene blue.

The adsorption isotherms of methylene blue were simulated by the mathematical equations of Langmuir ${ }^{11}$ and Freundlich ${ }^{12}$. The Langmuir model assumes the adsorption to occur on homogeneous surface of carbon by a monolayer adsorption and predicts a linear relation between $\mathrm{C}_{\mathrm{e}} / \mathrm{Q}_{\mathrm{e}}$ and $\mathrm{C}_{\mathrm{e}}$ can be rearranged as

$$
\frac{\mathrm{C}_{\mathrm{e}}}{\mathrm{Q}_{\mathrm{e}}}=\frac{1}{\mathrm{Q}_{\max }} \mathrm{C}_{\mathrm{e}}+\frac{1}{\mathrm{Q}_{\max } \mathrm{b}}
$$

Where $\mathrm{Q}_{\mathrm{e}}(\mathrm{mmol} / \mathrm{g})$ is adsorption capacity at equilibrium; $\mathrm{C}_{\mathrm{e}}$ is equilibrium concentration $(\mathrm{mmol} / \mathrm{L}) ; \mathrm{Q}_{\max }$ is the maximum adsorption capacity corresponding to complete monolayer coverage $(\mathrm{mmol} / \mathrm{g})$ and $\mathrm{b}$ is Langmuir constant $(\mathrm{L} / \mathrm{mmol})$.

The Freundlich model assumes surface heterogeneity which provides an empirical relationship between the adsorption capacity and equilibrium constant of the adsorbent.

$$
\log \mathrm{Q}_{\mathrm{e}}=\frac{1}{\mathrm{n}} \log \mathrm{C}_{\mathrm{e}}+\log \mathrm{k}_{\mathrm{f}}
$$

Where, $\mathrm{k}_{\mathrm{f}}\left[(\mathrm{mmol} / \mathrm{g})(\mathrm{L} / \mathrm{mmol})^{1 / \mathrm{n}}\right.$ and $\mathrm{n}(\mathrm{g} / \mathrm{L})$ are Freundlich constants related to adsorption capacity and adsorption affinity of the adsorbent respectively. 

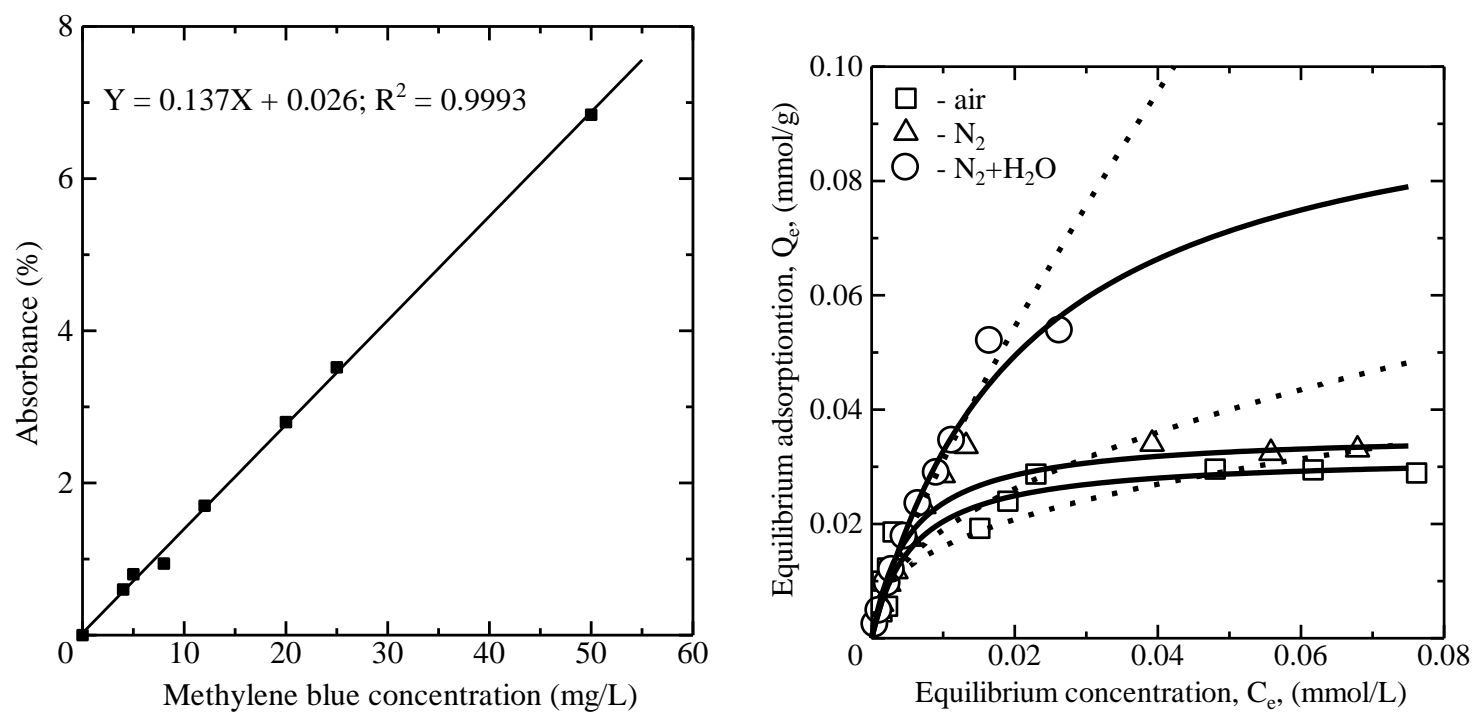

Figure 3 The calibration curve for aqueous solution of methylene blue.

Figure 4 The Adsorption isotherms of methylene blue solution on activated charcoal prepared from waste tire. Various points in the graph are experimental data points and solid \& dash line curves are calculated curve for Langmuir and Freundlich isothems.

The resulting adsorption isotherms are shown in Fig. 4. The adsorption isotherms data calculated from the Langmuir and Freundlich equations using the experimental data are listed in Table 1 . The adsorption values increased initially at an exponential rate and after reaching a certain critical value no such sharp rise was observed and adsorption attains equlibrium. The correlation coefficent values indicate the overall adsorption isotherms were better fit to Langmuir model in comparision to Freundlich model. These behaviours are expected to be due to the surface homogenity.

Table 1: Adsorption isotherms data obtained from Langmuir and Freundlich equations

\begin{tabular}{l|llllllll}
\hline Adsorbent & \multicolumn{2}{|l}{ Langmuir model } & & & \multicolumn{4}{c}{ Freundlich model } \\
& $Q_{\max }$ & $b$ & $R^{2}$ & $\Delta G(\mathrm{~kJ} / \mathrm{mol})$ & $S_{\text {area }}$ & $K_{f}$ & $N$ & $R^{2}$ \\
\hline Type I & 0.032 & 176.40 & 0.9876 & -29.92 & 38 & 0.093 & 2.67 & 0.7521 \\
Type I & 0.036 & 191.19 & 0.9916 & -30.13 & 43 & 0.163 & 2.16 & 0.8353 \\
Type III & 0.092 & 52.73 & 0.9991 & -26.93 & 110 & 1.309 & 1.23 & 0.9892 \\
\hline
\end{tabular}

According to the Langmuir data, the maximum adsorption capacities $\left(\mathrm{Q}_{\max }\right)$ of methylene blue for types I, II and III are $0.032,0.036$ and $0.092 \mathrm{mmol} / \mathrm{g}$, respectively. The variation in the adsorption capacities is attributed to the difference in the relative number of pores and hence to the active surface area of the adsorbents. The Langmuir constant ' $b$ ' is related to the free energy change of adsorption $(\Delta \mathrm{G})$ according to the following formula ${ }^{13}$ : 


$$
\Delta \mathrm{G}=-\mathrm{RT} \ln (1000 \mathrm{~b})
$$

Where $\mathrm{R}$ is gas constant, $8.314 \mathrm{~J} /(\mathrm{mol} \mathrm{K})$ and $\mathrm{T}$ is temperature in Kelvin. The Gibbs free energy indicates the degree of spontaneity of the adsorption process. The negative values reflect the favorable adsorption process.

\section{Kinetics of methylene blue adsorption}

In the present work, for the investigation of the rate law describing the adsorption capacity, kinetic data obtained from batch experiments were analyzed using the equations namely first order equation ${ }^{14}$ and the psuedo-second order equation ${ }^{15}$. The equations were rearranged to obtain the linear form as follows:

$$
\begin{aligned}
& \log _{10}\left(\mathrm{Q}_{\mathrm{e}}-\mathrm{Q}_{\mathrm{t}}\right)=\log _{10} \mathrm{Q}_{\mathrm{e}}-\frac{\mathrm{K}_{1}}{2.303} \mathrm{t} \\
& \frac{\mathrm{t}}{\mathrm{Q}_{\mathrm{t}}}=\frac{1}{\mathrm{~K}_{2}} \mathrm{Q}_{\mathrm{e}}{ }^{2}+\frac{1}{\mathrm{Q}_{\mathrm{e}}} \mathrm{t}
\end{aligned}
$$

The calculated data from the plots of $\log _{10}\left(Q_{e}-Q_{t}\right)$ and $t / Q_{t}$ as a function of reaction time are presented in Table 2. The correlation coefficient values $\left(R^{2}\right)$ of the plots of equation (7) and (8) were 0.8760 and 0.9557 , respectively. Furthermore, the $Q_{e}$ value obtained from the equation (8)

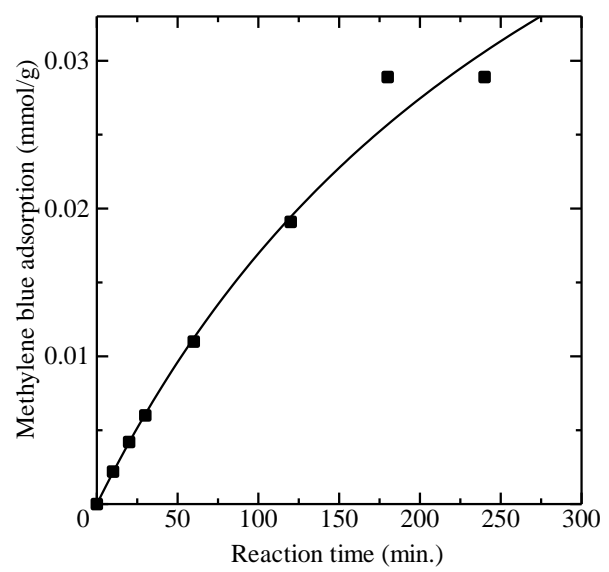

Figure 5 Plot of methylene blue adsorption as a function of reaction time. Solid line curve is calculated curve for pseudo-second order rate equation.

was $0.072 \mathrm{mmol} / \mathrm{g}$ comparable with the $\mathrm{Q}_{\max }$ value (0.0921) obtained from Langmuir equation (4). These data indicated that the pseudo-second order reaction model is the better fitting for methylene blue adsorption by type (III) adsorbent.

A plot of methylene blue adsorption as a function of reaction time is shown in Fig. 5. The points ( $\square$ ) in the figure are experimental data and the solid line curve is the calculated curve obtained from equation (8) and Table 2. This rapid adsorption of methylene blue by activated charcoal for about $180 \mathrm{~min}$ and thereby attaining towards equilibrium is in accordance with the previous report ${ }^{16}$. The rapid step is thought to be due to the abundant availability of active sites on the sorbent material, and as these sites become increasingly occupied, the sorption becomes less efficient and slower. 
Table 2: Kinetic data for the adsorption of methylene blue on type (III) activated charcoal

\begin{tabular}{|c|c|c|c|}
\hline \multirow[t]{2}{*}{ Reaction order } & Rate constant [L.g/(mmol.min $)]$ & $Q_{e}$ value $(\mathrm{mmol} / \mathrm{g})$ & $\overline{R^{2}}$ \\
\hline & $K_{1}$ & & \\
\hline First order & $2.5 \times 10^{-2}$ & 0.057 & 0.8760 \\
\hline Psuedo-second order & $4.2 \times 10^{-2}$ & 0.072 & 0.9557 \\
\hline
\end{tabular}

\section{Conclusion}

Tire recycling is not a simple proposition. Transporting and storing tires is expensive and dangerous. A lot of space is required for dumping of waste tires because of its nature. The manufacture of new products from rubber crumb is the area most likely to grow, but the crumbing of waste tires is expensive and cannot be done at a profit under the current circumstances. The overall study showed that the waste tire can be a promising material for the preparation of activated charcoal. The specific surface area increased dramatically under the atmosphere of nitrogen and steam and the increase amount of methylene blue adsorption from 0.032 to $0.092 \mathrm{mmol} / \mathrm{g}$ by thus prepared activated charcoal is a significant achievement. The kinetics followed by this type (III) activated carbon was a psuedo second order equation. The rate constant and equilibrium adsorption values obtained from pseudo second order equation were found to $4.2 \times 10^{-2} \mathrm{Lg} /(\mathrm{mmol} . \mathrm{min})$ and $0.0720 \mathrm{mmol} / \mathrm{g}$ respectively.

\section{References}

1. N.B. Amari, Preparation of Activated Carbons from waste tyres char impregnated with potassium hydroxide and carbon dioxide gasification, Master's thesis, University Sains Malaysia (2008).

2. E.L.K. Mui, D.C.K. Ko and G. McKay, Carbon, 2004, 42, 2789.

3. N.B. Amari, R. Zakaria and M.Z. Bakar, Pertanika J. Sci. Technol., 2009, 17, 371.

4. R. Helleur, N. Popovic, M. Ikura, M. Stanciulescu and D. Liu, J. Anal. Appl. Pyrol., 2001, 58-59, 813.

5. M. Streat, J.W. Patrick, M.J.C. Perez, Water Res., 1995, 29(2), 467.

6. J.L. Allen, J.L. Gatz, P.C. Eklund, Carbon, 1999, 37, 1485.

7. T.A. Brady, M. Rostam-Abadi and M.J. Rood, Gas Sep. Purif., 1996, 10(2), 97.

8. P. Williams, S. Besler, and T. Taylor, Fuel, 1990, 69, 1474.

9. S. Mopoung, J. Microsc. Soc. Thailand, 2008, 22, 15.

10. S. Mowry and P.J. Ogren, J. Chem. Educ., 2001, 31,109.

11. I.J. Langmuir, J. Amer. Chem. Soc., 1918, 40, 1361.

12. H. Freundlich and W. Hetler, J. Amer. Chem. Soc., 1939, 61, 2228.

13. V.K. Jha and S. Hayashi, J. Hazard. Mater., 2009, 169, 29.

14. S. Lagergreen and B.R. Svenska, Veternskapsakad Handlinger, 1898, 24, 1.

15. Y.S Ho, W. T. Chiu, C. S. Hsu, C. T. Huang, Hydrometallurgy, 2004, 73, 55.

16. M. Asadullah, M. Asaduzzaman, M.S. Kabir, M. G. Mostafa and T. Miyazawa, J. Hazard. Mater., 2010, 174, 437. 